\title{
Current Treatment Strategies in Metastasized Differentiated Thyroid Cancer
}

\author{
Michael C. Kreissl ${ }^{1}$, Marcel J.R. Janssen², and James Nagarajah ${ }^{2,3}$ \\ ${ }^{1}$ Department of Radiology and Nuclear Medicine, University Hospital Magdeburg, Magdeburg, Germany; ${ }^{2}$ Department of Radiology \\ and Nuclear Medicine, Radboud University Medical Center, Nijmegen, The Netherlands; and ${ }^{3}$ Department of Nuclear Medicine, \\ University Hospital Essen, University of Duisburg-Essen, Duisburg, Germany
}

Learning Objectives: On successful completion of this activity, participants should be able to (1) judge the prognosis of patients harboring metastasized differentiated thyroid cancer; (2) identify suitable treatment regimens considering the characteristics of the tumor and the patient's general condition; and (3) and know the basics of radioiodine treatment, TKI treatment, and redifferentiation treatment of metastasized DTC.

Financial Disclosure: Dr. KreissI has participated in advisory boards and given talks for Sanofi, Eisai, GE, AstraZeneca, Ipsen, Novartis, and Bayer Healthcare and receives research funding from GE Healthcare, AstraZeneca, Eisai, and Sanofi. The other authors of this article have indicated no other relevant relationships that could be perceived as a real or apparent conflict of interest.

CME Credit: SNMMI is accredited by the Accreditation Council for Continuing Medical Education (ACCME) to sponsor continuing education for physicians. SNMMI designates each JNM continuing education article for a maximum of 2.0 AMA PRA Category 1 Credits. Physicians should claim only credit commensurate with the extent of their participation in the activity. For CE credit, SAM, and other credit types, participants can access this activity through the SNMMI website (http://www.snmmilearningcenter.org) through January 2022.

On successful completion of this activity one should be able to judge the prognosis of patients harboring metastasized differentiated thyroid cancer (DTC); identify suitable treatment regimens, taking into account the characteristics of the tumor and the patient's general condition; and know the basics of radioiodine treatment, tyrosine kinase treatment, and redifferentiation treatment for metastasized DTC.

Key Words: metastasized thyroid cancer; radioiodine refractory thyroid cancer; tyrosine kinase inhibitor; redifferentiation

J Nucl Med 2019; 60:9-15

DOI: 10.2967/jnumed.117.190819

\section{I} the United States, thyroid cancer (TC) is the fifth most common cancer in women; a total of about 57,000 new cases occurred in women and men in 2015 (1). The worldwide rise in the incidence of differentiated TC (DTC) during the last few decades has been attributed mostly to an increased use of diagnostic imaging, especially ultrasound. However, recently published data from the Surveillance, Epidemiology, and End Results registry clearly indicate that it is not only the incidence of small TC that is increasing but the incidence of larger tumors as well (2). Therefore, a screening effect is not likely to be the only explanation for the rising incidence. Moreover, Lim et al. (2) observed an increase in disease-specific mortality, which is somewhat surprising because treatment has improved during the last few decades. Therefore, it is even more important to have a profound knowledge of the characteristics of the disease, especially in an advanced stage, since these tumors

Received Feb. 14, 2018; revision accepted Sep. 5, 2018.

For correspondence or reprints contact: James Nagarajah, Radboud University Nijmegen Medical Centre, Department of Radiology and Nuclear Medicine, P.O. Box 9101, 6500 HB Nijmegen, Netherlands.

E-mail: james.nagarajah@radboudumc.nl

Published online Sep. 6, 2018.

COPYRIGHT (c) 2019 by the Society of Nuclear Medicine and Molecular Imaging. often require multidisciplinary management using multiple imaging and treatment modalities. DTCs exhibit a broad range of clinical behavior-from indolent tumors with a high affinity to radioiodine and a low mortality to a rather aggressive behavior with low or no uptake of radioiodine, that is, in poorly differentiated TC.

In this continuing education article, we describe the treatment modalities available for patients with metastasized DTC.

\section{BACKGROUND ON ADVANCED/METASTASIZED DTC}

About $10 \%$ of patients with DTC have distant metastases at presentation or develop distant metastases during follow-up. When distant metastases are discovered, they are usually in the lungs or bones (3). In less than $5 \%$ of patients presenting with distant metastases are other organs involved, especially liver, brain, and skin. Some patients with oligometastases can still be cured by local therapeutic measures (surgery or radiofrequency/cryoablation); in other cases, systemic treatment may be postponed this way $(4,5)$.

In general, in metastatic DTC, the extent of radioiodine uptake plays a crucial role in the prognosis (6). Extent is variable, depending on the histologic subtype (papillary, follicular, or poorly differentiated). Radioiodine therapy is without doubt the most effective treatment in metastasized DTC, with limited side effects (Table 1). If tumor deposits take up radioiodine, this treatment is possibly curative. The overall survival after diagnosis of metastatic disease in patients with radioiodine uptake in the tumor was $56 \%$ at $10 \mathrm{y}$, $45 \%$ at $15 \mathrm{y}$, and $40 \%$ at $20 \mathrm{y}$, compared with $10 \%$ at $10 \mathrm{y}$ and $6 \%$ at $15 \mathrm{y}$ in patients without iodine uptake (6). If the metastases can be completely cured by radioiodine therapy, the overall 10-y survival is $92 \%$, compared with $29 \%$ in patients with residual disease.

Also, thyroid-stimulating hormone (TSH) suppressive therapy ( TSH $<0.1 \mathrm{mU} / \mathrm{L}$ ) is known to delay or slow progression in metastasized TC, resulting in an improved overall survival as compared with patients without TSH suppression (7).

Besides histology, a variety of biomarkers, such as high ${ }^{18} \mathrm{~F}-\mathrm{FDG}$ avidity, have also been associated with an increased aggressiveness in DTC (8). In the last decade, significant knowledge has been gained on the tumorigenesis of DTC. Especially, mutations of the oncogene 
TABLE 1

Dosage and Side Effects for Sorafenib and Lenvatinib

\begin{tabular}{ccc}
\hline \multicolumn{1}{c}{ Parameter } & \multicolumn{1}{c}{ Sorafenib } & Lenvatinib \\
\hline Dose & $2 \times 400 \mathrm{mg}$ orally & $1 \times 24 \mathrm{mg}$ orally \\
$\begin{array}{c}\text { Most higher-grade } \\
(3+4) \text { toxicities }\end{array}$ & $\begin{array}{c}\text { Hand-foot } \\
\text { syndrome, 20.3\% }\end{array}$ & $\begin{array}{c}\text { Hypertension, } \\
41.8 \%\end{array}$ \\
& Hypertension, 9.7\% & Proteinuria, 10\% \\
& Diarrhea, 5.8\% & Diarrhea, 8.0\% \\
\hline & Fatigue, 5.8\% & Weight loss, 9.6\% \\
\hline Dose modification & Weight loss, 5.8\% & Fatigue, 4.6\% \\
\hline Cessation & $78 \%$ & \\
\hline Reduction & $19 \%$ & $14 \%$ \\
\hline Pausing & $64 \%$ & $68 \%$ \\
\hline
\end{tabular}

$B R A F-V 600 E$ and the TERT promoter are known to convey a more aggressive tumor spread and reduced or absent uptake of radioiodine, as well as a reduced overall survival (9-11).

New targeted drugs have recently been registered for the treatment of advanced, progressive disease. Also, new ways of redifferentiation treatment were successfully evaluated, along with other experimental approaches.

Overall, the treatment modalities available for DTC patients can be classified as TSH-suppressive therapy, radioiodine treatment, locoregional and adjuvant/adjunctive treatments, targeted systemic treatment, or redifferentiation and other novel therapeutic approaches.

\section{TSH-SUPPRESSIVE THERAPY}

In patients with distant metastases, TSH-suppressive therapy has been shown to prolong progression-free survival $(7,12)$. However, long-term TSH suppression may increase the incidence or severity of cardiac arrhythmias and reduce bone density $(13,14)$. The dose of levothyroxine should be adjusted to obtain a TSH value of $0.1 \mathrm{mU} / \mathrm{L}$ or slightly below, since further suppression to an undetectable level has not been shown to further improve clinical outcomes (15).

\section{TREATMENT WITH RADIOIODINE}

Even though radioiodine treatment has now been applied for more than $70 \mathrm{y}$, most of the data come from relatively small and retrospective series, without randomization between various strategies. Therefore, many issues are not (completely) clear and treatment practices vary widely (16).

Both iodide uptake and metabolism are decreased to a variable extent in DTC, in comparison with the normal thyroid, but can be stimulated by increasing TSH (17). For high-risk patients, there is strong evidence that disease-specific survival and disease-free survival are improved by treatment with high-dose radioiodine after surgery $(7,18)$. Patients with small, distant metastases with high iodide uptake and retention can even be cured by ${ }^{131} \mathrm{I}$ treatment, particularly in adolescents and young adults with papillary TC who present with diffuse micronodular lung metastases. In patients with larger distant metastases, it is more difficult to reach a cure, but good and long-lasting partial remissions can often be achieved with several treatments with high-dose radioiodine (6). Complete responses and a good prognosis are associated with younger age, well-differentiated histology, limited tumor size and extent of metastases, and high ${ }^{131}$ I uptake.

In patients with a complete response on imaging, the unstimulated thyroglobulin level may remain detectable in about $50 \%$ of cases. In many cases, thyroglobulin levels are low and stable or even decrease without further treatment (19). In a study in 124 patients in complete (morphologic) remission after ${ }^{131} \mathrm{I}$ treatment for distant metastases who were followed up for a mean of $8 \mathrm{y}$, only 7 relapses occurred (6).

In most centers, radioiodine treatments are performed with a fixed dose. In cases of widespread distant metastases, usually an empiric dose of $3.7-7.4 \mathrm{GBq}$ of ${ }^{131} \mathrm{I}$ is applied. There are no studies directly comparing $3.7,5.5$, and $7.4 \mathrm{GBq}$ as the first radioiodine treatment in metastatic DTC. However, it is logical that the higher the dose is to the metastatic deposit, the more pronounced will be the expected biologic effect. Sublethal dosing may lead to the survival of the more radioiodine-resistant tumor cell clones and reduce the effect of subsequent therapies. The frequency and intervals of radioiodine treatments remain variable, with some centers continuing radioiodine treatments as long as there is visible uptake in the metastases on posttreatment scans, but evidence that continuation of radioiodine improves prognosis is lacking. One dosimetry study reported that after 4 or more 3.7 - to $7.4-\mathrm{GBq}{ }^{131}$ I treatments, a lesion dose of more than 20 Gy could hardly ever be achieved (20). Another study showed that after a cumulative activity of $22 \mathrm{GBq}$ of ${ }^{131}$ I, no complete response could be achieved (6).

An empirically fixed dose does not consider the inter- or intraindividually variable uptake of radioiodine, which can be assessed by pre- and intratherapeutic dosimetry. Two aspects are important in this context: the lesion dose and the maximum safe dose (MSD). The effect of radioiodine treatment on a metastasis depends on the effective dose obtained (measured in Gy) and its sensitivity to ionizing radiation. Lymph node and lung metastases, which receive more than $80-100 \mathrm{~Gy}$, are likely to achieve a complete response. Lesions reaching $20-80$ Gy will probably partially respond, and lesions that reach less than 20 Gy will probably not respond (21-23). Regarding safety, the maximum dose that can be tolerated by the dose-limiting organ, mainly the bone marrow, should not be exceeded. The MSD is estimated to be around 2 Gy to the blood and bone marrow. Standard operational procedures for blood dosimetry (measuring activity in blood samples and in the whole body at several time points) have been published (24). Measurements show that fixed-dose treatments with 3.7-7.4 GBq of ${ }^{131}$ I may exceed the MSD in a subgroup of patients, especially in elderly patients $(25,26)$. However, in most patients the MSD is above $7.4 \mathrm{GBq}$ (26), and therefore, in selected patients, higher activities might be administrated as a single treatment (instead of fractionating the treatment). There are data showing good responses using a MSD in heavily pretreated patients (mean cumulative activity, $31 \mathrm{GBq}$ ) who were resistant to conventional fixed dose therapy, with $15 \%$ complete responses, $32 \%$ partial responses, and $40 \%$ stable disease (26). The most common side effects of radioiodine treatment are summarized in Table 2 (27).

\section{RADIOIODINE-REFRACTORY (RAIR) DISEASE}

RAIR disease is that for which treatment with ${ }^{131} \mathrm{I}$ is no longer effective and discontinuation has to be considered. Thus, this is an important landmark in the evaluation of metastasized DTC patients. The definition of RAIR TC is, however, somewhat vague. Currently, patients with one or several RAIR tumor manifestations 
TABLE 2

Possible Side Effects and Their Treatment in Patients Undergoing Radioiodine Therapy

\begin{tabular}{|c|c|c|}
\hline Side effect & Incidence & Treatment \\
\hline Nausea (usually without vomiting) & $\begin{array}{l}\sim 30 \% \text { of patients; incidence related to }{ }^{131} \mid \\
\text { activity administered }\end{array}$ & $\begin{array}{l}\text { Self-limited; resolves within a few days; } \\
\text { antiemetic medication diminishes symptoms }\end{array}$ \\
\hline Tenderness in neck/thyroiditis & Rare in cases of small remnants & $\begin{array}{l}\text { Self-limited; may require symptomatic } \\
\text { treatment only in cases of large remnants }\end{array}$ \\
\hline $\begin{array}{l}\text { Sialadenitis/salivary gland } \\
\text { dysfunction }\end{array}$ & $\begin{array}{l}\text { Measurable in most patients; also } 6-12 \text { mo } \\
\text { after treatment, but usually leading to } \\
\text { chronic symptoms only after high } \\
\text { cumulative activities }(30)\end{array}$ & $\begin{array}{l}\text { Sour liquids and sweets may reduce incidence, } \\
\text { although there are conflicting data; these } \\
\text { should not be used in first } 24 \mathrm{~h} \text { after }{ }^{131} \mathrm{I} \\
\text { administration }(31,32)\end{array}$ \\
\hline Bone marrow dysfunction & $\begin{array}{l}\text { Transient decrease in thrombocytes/ } \\
\text { leukocytes, with nadir at } 4-6 \text { wk in up to } \\
25 \% \text { of patients (especially elderly) }\end{array}$ & $\begin{array}{l}\text { Usually resolves spontaneously within a few } \\
\text { weeks; chronically suppressed bone marrow } \\
\text { function may be observed in (especially } \\
\text { elderly) patients who received high } \\
\text { cumulative activities }\end{array}$ \\
\hline Gonadal dysfunction & $\begin{array}{l}\text { In } 30 \% \text { of men, transient oligospermia with } \\
\text { increased FSH (33) }\end{array}$ & $\begin{array}{l}\text { After single dose, is usually (but not always) } \\
\text { reversible; may become definitive after } \\
\text { several treatments; pretreatment sperm } \\
\text { banking may be offered }\end{array}$ \\
\hline
\end{tabular}

are considered as ${ }^{131} \mathrm{I}$ refractory. Another criterion is progression of lesions on cross-sectional imaging within a short period, that is, 6 or 12 mo after radioiodine therapy, regardless of radioiodine avidity. Moreover, patients with disease progression after radioiodine treatment with a cumulative activity of $22.2 \mathrm{GBq}$ or patients showing highly ${ }^{18}$ F-FDG-avid lesions on PET are considered as RAIR as well (28). A disadvantage of these definitions is the lack of knowledge about the amount of ${ }^{131}$ I taken up by the target lesion. The need for a dosimetry approach in these patients and its application was discussed in a review recently published in this journal (29).

As long as disease is stable or only slowly progressing, and tumor load is low, patients can remain without treatment with a good quality of life. If disease progresses rapidly (reflected by a thyroglobulin doubling time $<1$ y or a significant increase in tumor volume on imaging) or is symptomatic and cannot be handled by local treatments, other options are needed, such as targeted treatment with tyrosine kinases (TKIs) or experimental redifferentiation treatment, which will be discussed later.

\section{LOCOREGIONAL AND ADJUVANT OR ADJUNCTIVE TREATMENTS}

Various locoregional treatment options are available to address metastases to different organs, such as surgery, radiotherapy, thermal/ ethanol ablation or cryoablation, and embolization. However, in most patients with distant metastases of DTC, these treatments have to be considered palliative. Also, the data on all these measures are scarce, and no treatment modality has yet shown a survival benefit in the setting of metastatic DTC.

In cases of oligometastatic RAIR disease, cure might be achievable with local treatment, but staging should be thorough, preferably including ${ }^{18} \mathrm{~F}$-FDG PET/CT, to exclude more widespread metastatic disease.

In a palliative setting, local interventions should be limited to either addressing the pacemaker lesion, that is, a single rapidly progressive metastasis, or to obtaining control in an area at risk for tumor-associated complications, such as the neck, especially near vulnerable structures such as vessels, esophagus, and trachea.

External-beam radiotherapy is an effective way to treat not only bone metastases but also tumor deposits in the neck (30). Especially in cases of multiple recurrence after neck lymph node dissections or in cases of diffuse extranodal localizations, external-beam radiotherapy of the neck should be considered.

Lung metastases rarely lead to loss of organ function and often respond well to radioiodine treatment; therefore, local interventions, except for histologic verification, are usually not necessary.

Brain metastases should, if not radioiodine-avid, be treated by resection or external-beam radiotherapy (31).

In terms of adjuvant or adjunctive treatments, antiresorptive therapy should be considered in patients with bone metastases, even though the data on this topic are limited (32). Also, according to the current American Thyroid Association guideline, peri- and postmenopausal women at risk for bone loss should be considered for adjunctive therapy with calcium supplements, vitamin $\mathrm{D}$, and other bone-enhancing agents (31).

\section{TKI TREATMENT OPTIONS}

In the last decade, significant knowledge has been gained, particularly in the alteration of signaling pathways in DTC $(33,34)$. New inhibitors have been developed in the past few years targeting multiple TKIs. A selection of new substances can be found in Table 3 .

Multiple phase 2 and 3 clinical trials using TKI have been performed on RAIR advanced differentiated TC. The results of the phase 3 trials can be found in Table 4 .

Sorafenib was studied in 417 patients worldwide with progressing DTC. Response rates using RECIST 1.0 were $12 \%$ on verum as compared with $0.5 \%$ on placebo (35). The treatment prolonged progression-free survival from 5 to 11 mo. No significant benefit in overall survival was observed, as can at least in part be attributed to a significant number of patients receiving open-label medication after progression. Dose modifications due to toxicities were necessary 
TABLE 3

Inhibiting Concentrations $\left(\mathrm{IC}_{50}\right)$ for Various Targets of TKIs

\begin{tabular}{lccccccccc}
\hline \multicolumn{1}{c}{ Drug } & VEGFR1 & VEGFR2 & VEGFR3 & BRAF & RET & PDGFR & EGFR & c-KIT & Reference \\
\hline Sorafenib & & 90 & 20 & 22 & 47 & 57 & 68 & $(43)$ \\
Lenvatinib & 22 & 4.0 & 5.2 & & & 39 & 6,500 & 5.2 & $(44)$ \\
Vandetanib & 1,600 & 40 & 110 & & 130 & & 500 & $(36,45)$ \\
Cabozantinib & & 0.035 & & 4 & 234 & & $(46)$ \\
Pazopanib & 10 & 30 & 47 & & 2,800 & 84 & $(47)$ \\
Sunitinib & 2 & $4-9$ & 17 & & $41-100$ & 2 & $(36,48,49)$
\end{tabular}

PDGRF = platelet-derived growth factor receptor; EGFR = epithelial growth factor receptor.

Lower $\mathrm{IC}_{50}$ values indicate stronger inhibition.

in $78 \%$ of patients. The drug was approved in October 2013 by the Food and Drug Administration for the treatment of locally recurrent or metastatic, progressive RAIR DTC.

Data from a phase 3 trial using lenvatinib in advanced DTC were published more recently (36). Here, the overall response rate, using RECIST 1.1 , was $65 \%$ in the treatment group versus $2 \%$ on placebo, and the median progression-free survival was 18 versus 4 mo. Also, in this trial significant differences in the overall survival could not be observed because of confounding by patients who switched to openlabel drug after progression. However, in subgroup analysis, an improved overall survival was found in patients $65 \mathrm{y}$ or older in the verum group as compared with placebo (35). An example of the effect of lenvatinib can be found in Figure 1. Because of toxicities, dosing had to be modified in $82 \%$. The drug has been approved in the United States since February 2015 for the treatment of patients with locally recurrent or metastatic, progressive RAIR DTC. Currently, a phase II clinical trial of lenvatinib in patients with RAIR

TABLE 4

Results of Phase 3 Studies in DTC

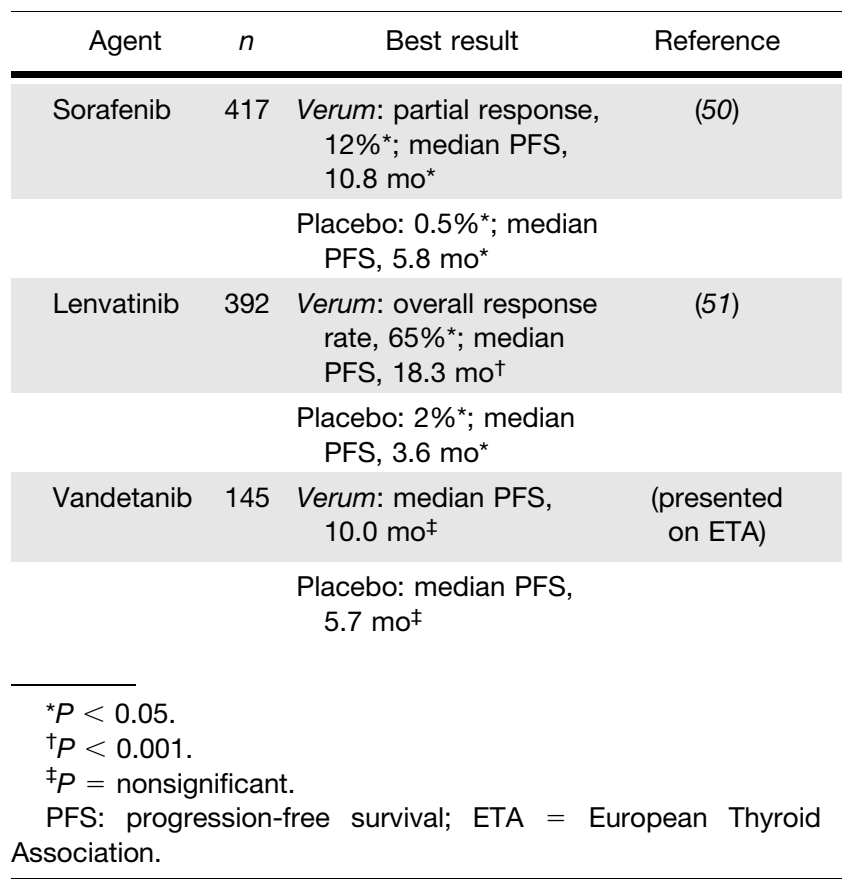

DTC is ongoing to evaluate whether an oral starting dosage of $18 \mathrm{mg}$ daily will provide comparable efficacy to the regular 24-mg starting dosage while improving the toxicity profile.

\section{Practical Aspects of TKI Treatment in Advanced TC}

Systemic therapy with TKI is a purely palliative, resulting in tumor shrinkage or a prolongation of progression-free survival in a

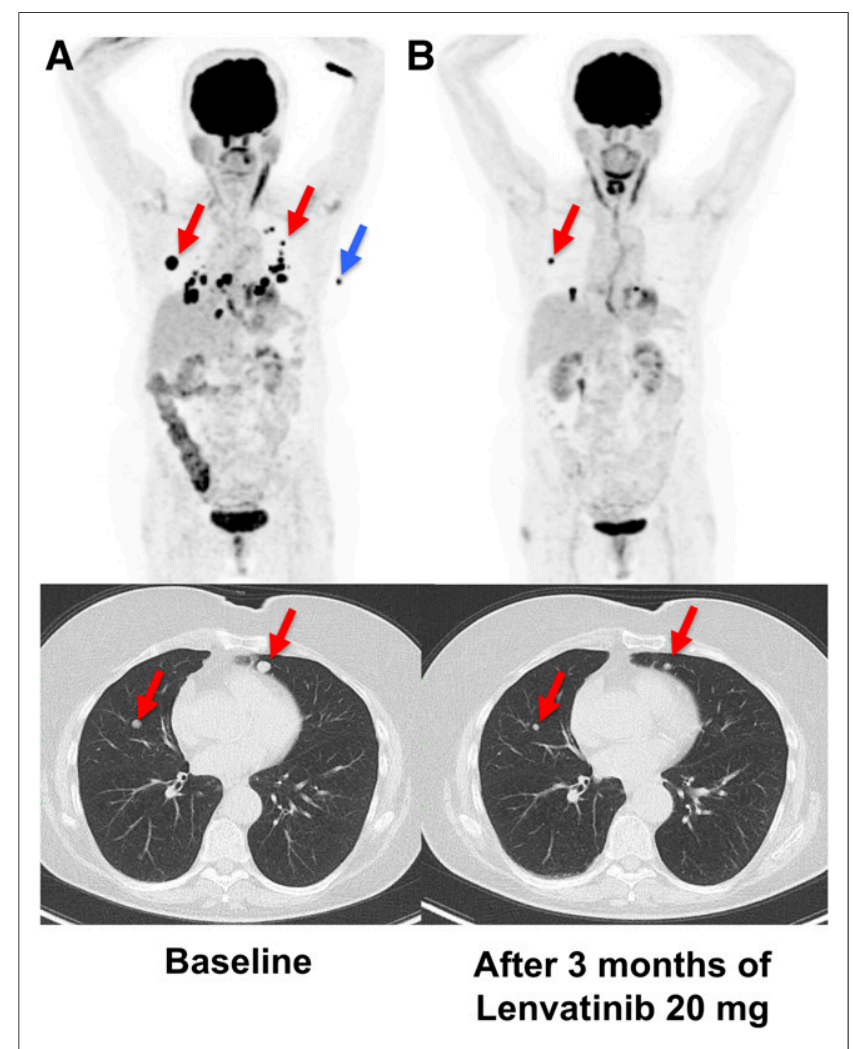

FIGURE 1. A 75-y-old woman with radioiodine-negative metastasized follicular TC. (A) Maximum-intensity projection of ${ }^{18} \mathrm{~F}$-FDG PET (top) and CT of lung before start of TKI therapy. (B) Maximum-intensity projection of ${ }^{18} \mathrm{~F}$-FDG PET (top) and CT of lung after 3 mo of lenvatinib, $20 \mathrm{mg}$ daily. Highly ${ }^{18} \mathrm{~F}-\mathrm{FDG}$-avid lung metastases (red arrows) show strong decrease in glucose metabolism, many becoming undetectable on PET. Significant decrease in size can be observed on CT. Softtissue metastasis in left breast (blue arrow) is no longer visible on follow-up PET. 
variable percentage of treated patients. Toxicities may severely impair quality of life if they are not addressed adequately. First, it is important to determine whether a patient definitely requires systemic therapy. In patients with locally progressive TC, locoregional therapies such as radiotherapy or palliative surgery should be preferred because of their favorable spectrum of side effects. The labels for both approved drugs are similar, indicating that these substances should be used only in advanced and progressive RAIR disease.

Education of the patient before the start of therapy plays an important role because the probability and severity of the most frequent toxicities of TKIs may be lowered by preventive measures, that is, manicure, pedicure, or proper treatment of preexisting arterial hypertension. Also, general supportive means are to be considered to maintain the patient's quality of life (37).

In general, it is advisable to discuss all DTC cases with a potential indication for TKI in an interdisciplinary tumor board and have systemic therapies performed or overseen by specialized centers.

\section{During TKI Treatment}

Side effects, which often occur during the course of TKI treatment, have to be addressed appropriately to maintain quality of life because the drugs need to be administered continuously to keep the tumor under control (37). Many toxicities such as diarrhea, hypertension, fatigue, weight loss, and hand-foot skin reaction are also observed with other antitumor drugs and in other cancers, and their management is alike. Especially for sorafenib, which has long been approved for the treatment of other malignancies, there is considerable knowledge of how to treat side effects once they occur (37-39). On the management of lenvatinib therapy, recently a comprehensive review article was published (40). However, the frequency and spectrum of side effects and the percentage of patients needing dose modification or cessation of therapy vary between different TKIs (Table 2). TSH should be monitored every $4 \mathrm{wk}$ at the beginning of therapy, since TKI therapy is known to produce elevated TSH levels.

Restaging has to be performed regularly, every 3-6 mo, depending on the clinical situation. Because many of the DTCs that require TKI treatment have antibodies interfering with determination of thyroglobulin or are poorly differentiated with often inadequately low thyroglobulin levels, imaging plays an important role in addition to the thyroglobulin. More details on the management of advanced DTC may be found in the current American Thyroid Association guideline (31).

\section{Pausing, Stopping, or Switching TKI Therapy}

Because of side effects, dose modifications are common in TKI therapies. There is no clear recommendation on how to proceed if tumor progression under TKI is observed. Out of common sense, treatment should be stopped and possibly switched if progress is generalized or if complications are expected from progressing tumor manifestations that cannot be controlled by local therapeutic options. It remains open how a slow, general progression after an initial good response, or how an oligotropic or localized progression, should be handled. Data from other tumor entities suggest that a progression according to RECIST does not necessarily go along with a clinically relevant progression, because patients potentially might still benefit if most lesions are stable during systemic therapy (41).

Data published for DTC indicate that cancers that have become resistant to the first line of TKI therapy may show a response to a second line of TKI (42-44). Also, data from the phase 3 lenvatinib trial indicate efficacy of the drug as a secondline treatment (36).

\section{REDIFFERENTIATION}

Experimental approaches for restoring radioiodine avidity have historically yielded disappointing results (45-47). Recently, MAPK signaling moved into the focus as an effective treatment option for patients with RAIR TC, mainly because of convincing preclinical results $(48,49)$.

\section{MAPK Pathway Critical for Dedifferentiation of TC}

Increasing understanding of the underlying mechanism responsible for development of RAIR and identifying targetable drivers supporting this conversion lead to a change in treatment concepts $(34,50)$. The $B R A F^{V 600 E}$ mutation is the most common genetic alteration in PTC, not only showing a more aggressive clinical behavior but also being a major driver for developing RAIR through suppression of key genes involved in iodine uptake and metabolism $(51,52)$. Additionally, RAS mutations are found in approximately $10 \%-20 \%$ of PTCs and $40 \%-50 \%$ of FTCs, which are responsible for suppression of these genes as well, resulting in dedifferentiation (53).

\section{Inhibition of MAPK Restores Sodium lodide Symporter Expression in RAIR TC}

Preclinical studies revealed that MAPK inhibition leads to restoration of sodium iodide symporter expression in previously RAIR TC $(48,49)$. The inhibition of MAPK signaling can be pharmacologically performed through inhibition of BRAF or downstream of BRAF. Chakravarty et al. and Nagarajah et al. demonstrated in in vitro and in vivo TC models that inhibition of MAPK signaling results in upregulation of iodine metabolismrelated genes and, consequently, that these tumors become sensitive to radioiodine treatment $(48,49)$.

\section{Clinical Studies}

Two prospective studies have been published to date investigating the inhibition of MAPK signaling to redifferentiate RAIR TC patients.

Ho et al. included 20 patients in a prospective study on RAIR disease (54). ${ }^{124}$ I PET dosimetry was performed before and after 4 wk of treatment with selumetinib, a selective inhibitor of mitogenactivated protein kinase. Of the 20 evaluable patients, $12(60 \%)$ had new or increased ${ }^{124} \mathrm{I}$ incorporation after selumetinib. For 8 $(40 \%)$ patients, the second ${ }^{124}$ I PET scan predicted that the lesional absorbed radiation dose would be at least $20 \mathrm{~Gy}$; these patients were continued on selumetinib and went on to receive therapeutic ${ }^{131} \mathrm{I}$. All 5 study patients with NRAS mutant tumors were treated with ${ }^{131} \mathrm{I}$, too. By contrast, only 1 of $9 B R A F^{V 600 E}$ patients had selumetinib-induced increases in ${ }^{124} \mathrm{I}$ incorporation warranting ${ }^{131}$ I treatment. Two of 3 RET/PTC and 1 of 3 wild-type patients also had greater iodine incorporation on the second ${ }^{124} \mathrm{I}$ PET scan, and one of each of those genotypes went on to be treated with ${ }^{131} \mathrm{I}$. Reduction in tumor size by RECIST was achieved in all 8 patients who received ${ }^{131}$ I with selumetinib; there were 5 confirmed partial responses and 3 with stable disease. Substantial decreases in thyroglobulin after radioiodine therapy were also achieved in all patients. All evaluable patients completed the full course of selumetinib without dose reduction or delay. These data provide the proof of concept that MAPK pathway inhibition can clinically reverse radioiodine resistance in $B R A F^{V 600 E}$ tumors 
but also argues that mitogen-activated protein kinase inhibitors may not be the most effective approach for inhibiting the pathway and enhancing iodine avidity in $B R A F^{V 600 E}$ tumors.

In another study Rothenberg et al. included 10 RAIR $B R A F^{V 600 E}$ patients (55). They were treated with a selective BRAF inhibitor, dabrafenib, $150 \mathrm{mg}$ orally twice daily, for $25 \mathrm{~d}$. Six of 10 patients $(60 \%)$ developed new radioiodine uptake while on dabrafenib and were treated with a fixed dose of $5.5 \mathrm{GBq}$ of ${ }^{131} \mathrm{I}$. Six months after treatment with radioiodine, 2 patients showed progression and 4 had stable disease. It is noteworthy that 3 patients who did not show any new radioiodine-avid lesions after dabrafenib showed stable disease as well. The differences in the measured thyroglobulin concentrations were not statistically significant.

Taken together, both studies demonstrate that pharmacologic inhibition of MAPK in RAIR TC patients opens a novel therapeutic option. However, the design of both studies needs to be analyzed critically to optimize the treatment for future studies. For instance, preclinical experiments show that sodium iodide symporter upregulation in RAIR TC is time-sensitive (49). In both presented clinical studies, the radioiodine treatment was applied after about 5-6 wk, which may have reduced the therapeutic effect of radioiodine because of reduced sodium iodide symporter expression in this time window. Patients included in the study by Ho et al. (54) underwent an ${ }^{124} \mathrm{I}$ PET-based dosimetry after $4 \mathrm{wk}$, and in cases of radioiodine-positive lesions, the patients underwent an additional ${ }^{131}$ I-based dosimetry as well. Here, stunning effects may have reduced the ${ }^{131} \mathrm{I}$ therapeutic effect. Rothenberg et al. (55) did not perform a dosimetry and used a standard activity of $5.5 \mathrm{GBq}$ of ${ }^{131} \mathrm{I}$. This amount of activity may be insufficient to treat these patients effectively, given the fact that metastatic radioiodine-avid TC patients are usually treated with $7.4 \mathrm{GBq}$ of ${ }^{131} \mathrm{I}$ or more. Particularly, after redifferentiation even higher activities should be considered, as demonstrated by Ho et al.

\section{Side Effects}

Toxicities attributed to selumetinib or dabrafenib were grade 1 or 2 in both studies and were consistent with adverse events reported in larger studies. Even though small-molecule inhibitor therapy is coupled with side effects, severe side effects are less likely because of the short period of treatment for RAIR patients.

\section{Practical Aspects of Redifferentiation Treatment in RAIR TC}

To date, redifferentiation treatment using MAPK inhibitors has to be considered an experimental approach. Therefore, there is no general recommendation yet in terms of either an optimal time window or an appropriate patient selection process. In some centers in Europe, patients with a low tumor load and no tumor-related symptom-patients who are not considered for TKI therapy-are deemed to be eligible for a redifferentiation therapy with MAPK inhibitors. However, patients in a progressive disease state showing no response to TKIs or in whom TKIs have to be discontinued because of side effects may be eligible for a redifferentiation treatment with MAPK inhibitors followed by a potential radioiodine therapy to slow or stabilize tumor progression. Because of the short-term drug treatment and most likely absence of severe side effects related to MAPK inhibitors in this setting, there is less risk to patients for this experimental approach.

\section{OTHER NOVEL TREATMENT APPROACHES}

Besides the above-discussed therapeutic approaches, there are a few reports about targeting other receptors, such as somatostatin receptors or prostate-specific membrane antigen, in RAIR
TC. Among the few studies reporting about somatostatin receptor expression on ${ }^{68} \mathrm{Ga}$-DOTATOC PET/CT imaging, only one published study has presented treatment data with ${ }^{90} \mathrm{Y}$ DOTATOC so far (56-58).

Prostate-specific membrane antigen was identified as another possible target in progressive RAIR TC; however, there have been only a few studies and case reports showing increased PSMA expression on ${ }^{68} \mathrm{Ga}$-PSMA ligand PET/CT, and no therapy data are available yet $(59,60)$. Therefore, the role of ${ }^{177} \mathrm{Lu}-\mathrm{PSMA}$ ligands as a treatment option has to be further elucidated.

\section{CONCLUSION}

Treatment of advanced thyroid cancer gets challenging once the tumors turn irresponsive to radioiodine. Currently, there are 2 registered TKIs for these patients; however, due to response rates and side effects, most of the centers apply these TKIs mostly for symptomatic patients. Redifferentiation, which is currently an experimental approach and needs further research, offers a promising approach for these patients.

\section{REFERENCES}

1. Siegel RL, Miller KD, Jemal A. Cancer statistics, 2015. CA Cancer J Clin. 2015; 65:5-29.

2. Lim H, Devesa SS, Sosa JA, Check D, Kitahara CM. Trends in thyroid cancer incidence and mortality in the United States, 1974-2013. JAMA. 2017;317:1338-1348.

3. Schlumberger M, Challeton C, De Vathaire F, et al. Radioactive iodine treatment and external radiotherapy for lung and bone metastases from thyroid carcinoma. J Nucl Med. 1996;37:598-605.

4. Bernier M-O, Leenhardt L, Hoang C, et al. Survival and therapeutic modalities in patients with bone metastases of differentiated thyroid carcinomas. J Clin Endocrinol Metab. 2001;86:1568-1573.

5. McWilliams RR, Giannini C, Hay ID, Atkinson JL, Stafford SL, Buckner JC. Management of brain metastases from thyroid carcinoma. Cancer. 2003;98:356-362.

6. Durante C, Haddy N, Baudin E, et al. Long-term outcome of 444 patients with distant metastases from papillary and follicular thyroid carcinoma: benefits and limits of radioiodine therapy. J Clin Endocrinol Metab. 2006;91:2892-2899.

7. Jonklaas J, Sarlis NJ, Litofsky D, et al. Outcomes of patients with differentiated thyroid carcinoma following initial therapy. Thyroid. 2006;16:1229-1242.

8. Robbins RJ, Wan Q, Grewal RK, et al. Real-time prognosis for metastatic thyroid carcinoma based on 2-[ $\left.{ }^{18} \mathrm{~F}\right]$ fluoro-2-deoxy-d-glucose-positron emission tomography scanning. J Clin Endocrinol Metab. 2006;91:498-505.

9. Elisei R, Ugolini C, Ugolini $C$, et al. $B R A F^{\mathrm{V} 600 \mathrm{E}}$ mutation and outcome of patients with papillary thyroid carcinoma: a 15-year median follow-up study. J Clin Endocrinol Metab. 2008;93:3943-3949.

10. Xing M, Liu R, Liu X, et al. BRAF V600E and TERT promoter mutations cooperatively identify the most aggressive papillary thyroid cancer with highest recurrence. J Clin Oncol. 2014;32:2718-2726.

11. Xing M. Association between BRAF V600E mutation and mortality in patients with papillary thyroid cancer. JAMA. 2013;309:1493.

12. Pujol P, Daures J-P, Nsakala N, Baldet L, Bringer J, Jaffiol C. Degree of thyrotropin suppression as a prognostic determinant in differentiated thyroid cancer. J Clin Endocrinol Metab. 1996;81:4318-4323.

13. Biondi B, Cooper DS. Benefits of thyrotropin suppression versus the risks of adverse effects in differentiated thyroid cancer. Thyroid. 2010;20:135-146.

14. Sawin CT, Geller A, Wolf PA, et al. Low serum thyrotropin concentrations as a risk factor for atrial fibrillation in older persons. N Engl J Med. 1994;331:12491252 .

15. Dieß1 S, Holzberger B, Mäder U, et al. Impact of moderate vs stringent TSH suppression on survival in advanced differentiated thyroid carcinoma. Clin Endocrinol (Oxf). 2012;76:586-592.

16. Seidlin SM, Marinelli LD, Oshry E. Radioactive iodine therapy: effect on functioning metastases of adenocarcinoma of the thyroid. JAMA. 1946;132:838-847.

17. Goldman JM, Line BL, Aamodt RL, Robbins RJ. Influence of triiodothyronine withdrawal time on ${ }^{131} \mathrm{I}$ uptake posthyroidectomy for thyroid cancer. $J$ Clin Endocrinol Metab. 1980;50:734.

18. Podnos YD, Smith D, Wagman LD, Ellenhorn JDI. Radioactive iodine offers survival improvement in patients with follicular carcinoma of the thyroid. Surgery. 2005;138:1072-1076. 
19. Biko J, Reiners C, Kreissl MC, Verburg FA, Demidchik Y, Drozd V. Favourable course of disease after incomplete remission on ${ }^{131} \mathrm{I}$ therapy in children with pulmonary metastases of papillary thyroid carcinoma: 10 years follow-up. Eur J Nucl Med Mol Imaging. 2011;38:651-655.

20. Sun F, Gerrard GE, Roberts JK, et al. Ten year experience of radioiodine dosimetry: is it useful in the management of metastatic differentiated thyroid cancer? Clin Oncol. 2017;29:310-315.

21. Maxon HR III, Smith HS. Radioiodine-131 in the diagnosis and treatment of metastatic well differentiated thyroid cancer. Endocrinol Metab Clin North Am. 1990;19:685-718.

22. Chiesa C, Castellani MR, Vellani C, et al. Individualized dosimetry in the management of metastatic differentiated thyroid cancer. $Q$ J Nucl Med Mol Imaging. 2009;53:546-561.

23. Maxon HR, Thomas SR, Hertzberg VS, et al. Relation between effective radiation dose and outcome of radioiodine therapy for thyroid cancer. $N$ Engl J Med. 1983;309:937-941.

24. Lassmann M, Luster M, Hänscheid H, Reiners C. Blood dosimetry and dose-rate effects after radioiodine therapy of differentiated thyroid cancer. $\mathrm{J} \mathrm{Nucl} \mathrm{Med}$. 2005;46:899.

25. Kulkarni K, Nostrand DV, Atkins F, Aiken M, Burman K, Wartofsky L. The relative frequency in which empiric dosages of radioiodine would potentially overtreat or undertreat patients who have metastatic well-differentiated thyroid cancer. Thyroid. 2006;16:1019-1023.

26. Tuttle RM, Leboeuf R, Robbins RJ, Qualey R, Pentlow KS, Larson SM. Empiric radioactive iodine dosing regimens frequently exceed maximum tolerated activity levels in elderly patients with thyroid cancer. $J$ Nucl Med. 2006;47:1587-1591.

27. Fard-Esfahani A, Emami-Ardekani A, Fallahi B, et al. Adverse effects of radioactive iodine-131 treatment for differentiated thyroid carcinoma. Nucl Med Commun. 2014;35:808-817.

28. Cabanillas ME, McFadden DG, Durante C. Thyroid cancer. Lancet. 2016;388: 2783-2795.

29. Nagarajah J, Janssen M, Hetkamp P, Jentzen W. Iodine symporter targeting with ${ }^{124} \mathrm{I} /{ }^{131} \mathrm{I}$ theranostics. J Nucl Med. 2017;58(suppl):34S-38S.

30. Ford D, Giridharan S, McConkey C, et al. External beam radiotherapy in the management of differentiated thyroid cancer. Clin Oncol (R Coll Radiol). 2003;15: 337-341.

31. Haugen BR, Alexander EK, Bible KC, et al. 2015 American Thyroid Association management guidelines for adult patients with thyroid nodules and differentiated thyroid cancer: the American Thyroid Association Guidelines Task Force on Thyroid Nodules and Differentiated Thyroid Cancer. Thyroid. 2016;26:1-133.

32. Vitale G, Fonderico F, Martignetti A, et al. Pamidronate improves the quality of life and induces clinical remission of bone metastases in patients with thyroid cancer. Br J Cancer. 2001;84:1586-1590.

33. Kondo T, Ezzat S, Asa SL. Pathogenetic mechanisms in thyroid follicular-cell neoplasia. Nat Rev Cancer. 2006;6:292-306.

34. Fagin JA, Wells SA Jr. Biologic and clinical perspectives on thyroid cancer. N Engl J Med. 2016;375:1054-1067.

35. Brose MS, Nutting CM, Jarzab B, et al. Sorafenib in radioactive iodine-refractory, locally advanced or metastatic differentiated thyroid cancer: a randomised, double-blind, phase 3 trial. Lancet. 2014;384:319-328.

36. Schlumberger M, Tahara M, Wirth LJ, et al. Lenvatinib versus placebo in radioiodine-refractory thyroid cancer. $N$ Engl J Med. 2015;372:621-630.

37. Resteghini C, Cavalieri S, Galbiati D, et al. Management of tyrosine kinase inhibitors (TKI) side effects in differentiated and medullary thyroid cancer patients. Best Pract Res Clin Endocrinol Metab. 2017;31:349-361.

38. Kreissl MC, Fassnacht M. Neue molekulare Therapien bei fortgeschrittenem differenziertem Schilddrüsenkarzinom. Der Nuklearmediziner. 2010;33:242-248.

39. Kreissl MC, Fassnacht M. Systemic treatment of advanced differentiated and medullary thyroid cancer. Nuklearmedizin. 2015;54:88-93.

40. Capdevila J, Newbold K, Licitra L, et al. Optimisation of treatment with lenvatinib in radioactive iodine-refractory differentiated thyroid cancer. Cancer Treat Rev. 2018;69:164-176.
41. Nishie K, Kawaguchi T, Tamiya A, et al. Epidermal growth factor receptor tyrosine kinase inhibitors beyond progressive disease: a retrospective analysis for Japanese patients with activating EGFR mutations. J Thorac Oncol. 2012;7: $1722-1727$.

42. Dadu R, Devine C, Hernandez M, et al. Role of salvage targeted therapy in differentiated thyroid cancer patients who failed first-line sorafenib. J Clin Endocrinol Metab. 2014;99:2086-2094.

43. Massicotte MH, Brassard M, Claude-Desroches M, et al. Tyrosine kinase inhibitor treatments in patients with metastatic thyroid carcinomas: a retrospective study of the TUTHYREF network. Eur J Endocrinol. 2014;170:575-582.

44. Cabanillas ME, de Souza JA, Geyer S, et al. Cabozantinib as salvage therapy for patients with tyrosine kinase inhibitor-refractory differentiated thyroid cancer: results of a multicenter phase II International Thyroid Oncology Group trial. J Clin Oncol. 2017;35:3315-3321.

45. Rosenbaum-Krumme SJ, Freudenberg LS, Jentzen W, Bockisch A, Nagarajah J. Effects of rosiglitazone on radioiodine negative and progressive differentiated thyroid carcinoma as assessed by ${ }^{124}$ I PET/CT imaging. Clin Nucl Med. 2012;37: e47-e52.

46. Coelho SM, Corbo R, Buescu A, Carvalho DP, Vaisman M. Retinoic acid in patients with radioiodine non-responsive thyroid carcinoma. J Endocrinol Invest. 2004;27:334-339.

47. Liu YY, van der Pluijm G, Karperien M, et al. Lithium as adjuvant to radioiodine therapy in differentiated thyroid carcinoma: clinical and in vitro studies. Clin Endocrinol (Oxf). 2006;64:617-624.

48. Chakravarty D, Santos E, Ryder M, et al. Small-molecule MAPK inhibitors restore radioiodine incorporation in mouse thyroid cancers with conditional BRAF activation. J Clin Invest. 2011;121:4700-4711.

49. Nagarajah J, Le M, Knauf JA, et al. Sustained ERK inhibition maximizes responses of BrafV600E thyroid cancers to radioiodine. J Clin Invest. 2016;126: 4119-4124.

50. Landa I, Ibrahimpasic T, Boucai L, et al. Genomic and transcriptomic hallmarks of poorly differentiated and anaplastic thyroid cancers. J Clin Invest. 2016; 126:1052-1066.

51. Durante C, Puxeddu E, Ferretti E, et al. BRAF mutations in papillary thyroid carcinomas inhibit genes involved in iodine metabolism. J Clin Endocrinol Metab. 2007;92:2840-2843.

52. Liu D, Hu S, Hou P, Jiang D, Condouris S, Xing M. Suppression of BRAF/MEK/ MAP kinase pathway restores expression of iodide-metabolizing genes in thyroid cells expressing the V600E BRAF mutant. Clin Cancer Res. 2007;13:13411349.

53. De Vita G, Bauer L, da Costa VMC, et al. Dose-dependent inhibition of thyroid differentiation by RAS oncogenes. Mol Endocrinol. 2005;19:76-89.

54. Ho AL, Grewal RK, Leboeuf R, et al. Selumetinib-enhanced radioiodine uptake in advanced thyroid cancer. $N$ Engl J Med. 2013;368:623-632.

55. Rothenberg SM, McFadden DG, Palmer EL, Daniels GH, Wirth LJ. Redifferentiation of iodine-refractory BRAF V600E-mutant metastatic papillary thyroid cancer with dabrafenib. Clin Cancer Res. 2015;21:1028-1035.

56. Binse I, Poeppel TD, Ruhlmann M, et al. ${ }^{68} \mathrm{Ga}$-DOTATOC PET/CT in patients with iodine- and ${ }^{18} \mathrm{~F}$-FDG-negative differentiated thyroid carcinoma and elevated serum thyroglobulin. J Nucl Med. 2016;57:1512-1517.

57. Campennì A, Pignata SA, Baldari S. Can peptide receptor radionuclide therapy (PRRT) be useful in radioiodine-refractory differentiated thyroid cancer? Endocrine. 2015;50:516-518.

58. Versari A, Sollini M, Frasoldati A, et al. Differentiated thyroid cancer: a new perspective with radiolabeled somatostatin analogues for imaging and treatment of patients. Thyroid. 2014;24:715-726.

59. Verburg FA, Krohn T, Heinzel A, Mottaghy FM, Behrendt FF. First evidence of PSMA expression in differentiated thyroid cancer using $\left[{ }^{68} \mathrm{Ga}\right]$ PSMA-HBED-CC PET/CT. Eur J Nucl Med Mol Imaging. 2015;42:1622-1623.

60. Lütje S, Gomez B, Cohnen J, et al. Imaging of prostate-specific membrane antigen expression in metastatic differentiated thyroid cancer using ${ }^{68} \mathrm{Ga}-\mathrm{HBED}$ CC-PSMA PET/CT. Clin Nucl Med. 2017;42:20-25. 